\title{
Incentivos competitivos e cooperativos em relações diádicas: um estudo de caso na cadeia de uvas orgânicas
}

\author{
Competitive and cooperative incentives in dyadic \\ relationships: a case study in the organic grape chain \\ Tatiane Pellin Cislaghi ${ }^{1,2}$ (D), Douglas Wegner $^{1}$ (D) , Luciana Marques Vieira ${ }^{3}$ \\ e Elieti Biques Fernandes ${ }^{1}$
}

\begin{abstract}
Resumo: Sistemas de incentivos têm como objetivo motivar e direcionar o comportamento dos participantes de relacionamentos interorganizacionais. Incentivos cooperativos baseiam-se no compartilhamento de benefícios e ganhos gerados na relação, enquanto os competitivos referem-se a recompensar os fornecedores com base em seu desempenho em relação a outros fornecedores. Tomando como base a lente teórica da Visão Relacional, o estudo teve como objetivo analisar como incentivos competitivos e cooperativos originários da empresa compradora influenciam os resultados econômicos de seus fornecedores. Uma pesquisa qualitativa foi realizada por meio de um estudo de caso, cuja unidade de análise foi a relação diádica em uma cadeia de suprimentos de produtos orgânicos. Os resultados demonstraram que a empresa compradora utiliza incentivos competitivos quando busca estimular os fornecedores a adotar comportamentos para evitar punições, especialmente em relação às atividades produtivas; já os incentivos cooperativos são utilizados para promover a troca de informações, transferência de conhecimentos e relações baseadas na confiança. Como contribuição teórica identificou-se que, no contexto da produção orgânica, além dos incentivos competitivos e cooperativos, as relações entre fornecedores e compradores são fortemente influenciadas por fatores externos, como os padrões das certificadoras e regulamentações internacionais.
\end{abstract}

Palavras-chave: relacionamentos interorganizacionais, produção orgânica, relações de poder, ganhos relacionais.

Data de submissão: 13 de maio de 2017. Data de aceite: 28 de julho de 2018.

1. Universidade do Vale do Rio dos Sinos (Unisinos), Porto Alegre (RS), Brasil. E-mails: tatiane.cislaghi@bento.ifrs.edu.br; dwegner@unisinos.br elieti_fernandes@hotmail.com

2. Instituto Federal de Educação, Ciência e Tecnologia do Rio Grande do Sul (IFRS), Bento Gonçalves (RS), Brasil.

3. Fundação Getúlio Vargas (FGV), São Paulo (SP), Brasil. E-mail: luciana.vieira@fgv.br 
Abstract: Incentive systems aim to motivate and direct the behavior of participants in inter-organizational relationships. Cooperative incentives are based on sharing of benefits and gains generated in relationship, while the competitive ones refer to rewarding suppliers based on their performance relative to other suppliers. Based on the Relational View lens, the study aimed to analyze how competitive and cooperative incentives from the purchasing company influence the economic results of its suppliers. A qualitative research was carried out through a case study, whose unit of analysis was the dyadic relationship in an organic products supply chain. The results showed that the purchasing company uses competitive incentives when it seeks to encourage suppliers to adopt behaviors in order to avoid punishment, especially in relation to productive activities. Cooperative incentives also promote information exchange, knowledge transfer and trust-based relationships. As a theoretical contribution, in the organic production context, it was identified that beyond the influence of competitive and cooperative incentives over the relations between buyer and suppliers there are external factors such as international certification standards and regulations, which exerts a strong influence on the studied relation.

Key-words: inter-organizational relationships, organic production, power relationships, relational rents.

Classificação JEL: M1, M19.

\section{Introdução}

A compreensão dos relacionamentos interorganizacionais (RIOs) no contexto das cadeias de suprimentos (CS) vem recebendo crescente atenção na literatura (Villena et al., 2011; Brito \& Miguel, 2017). Relacionamentos interorganizacionais caracterizam-se como transações contínuas, com fluxos e ligações que ocorrem entre uma organização e outra ou mais organizações em seu ambiente (Oliver, 1990), com o objetivo de propiciar o compartilhamento de benefícios, bem como de encargos e, ainda, potencializar a redução dos riscos nas relações de troca (Daugherty, 2011). Ao combinarem recursos por meio de articulações em seus relacionamentos, as organizações almejam a obtenção de vantagens competitivas que, de maneira individual, dificilmente seriam possíveis (Dyer \& Singh, 1998; Cheung et al., 2010; Dyer et al., 2018).

Embora a Gestão da Cadeia de Suprimentos (GCS) já tenha sido extensivamente analisada na área de operações (Chen \& Paulraj, 2004; Huang et al., 2014), a utilização de incentivos com o intuito de melhorar os resultados de díades é um campo recente e pouco explorado (Terpend \& Krause, 2015). Os incentivos representam uma ferramenta útil para as empresas compradoras que buscam gerenciar proativamente o desempenho do fornecedor (Sanders et al., 2011; Terpend \& Krause, 2015). No entanto, há poucos estudos empíricos que enfatizam como as organizações podem utilizar os tipos específicos de incentivos em benefício do desempenho de um fornecedor, ou, ainda, alinhar o comportamento de um fornecedor com os objetivos da empresa compradora (Krause et al., 2000; Datta \& Roy, 2013; Zimmermann \& Foerstl, 2014).

Com base no exposto, o objetivo do estudo é analisar como os incentivos competitivos e cooperativos originários da empresa compradora exercem influência nos resultados econômicos obtidos pelos fornecedores na cadeia de suprimentos de alimentos orgânicos. A unidade de análise é a relação diádica no processo de compra de uma matéria-prima específica. A pesquisa foi realizada com base na lente teórica da Visão Relacional (VR) (Dyer \& Singh, 1998; Dyer et al., 2018), que sugere que as empresas estabelecem ao longo do tempo relações competitivas e colaborativas (Braziotis et al., 2013; Viana et al., 2014). A perspectiva da Visão Relacional tem mostrado que as empresas criam valor nas parcerias quando identificam parceiros com recursos complementares, quando criam altos níveis de confiança informal, compartilham conhecimento e fazem investimentos personalizados para o parceiro (Dyer et al., 2018).

O estudo foi realizado em uma indústria de produtos orgânicos e nos seus fornecedores de uva orgânica. A linha de produtos é composta por sucos de uva, vinagres, farinha de semente e de casca de uva e óleos de semente de uva. A opção por essa cadeia se justifica porque os fornecedores de produtos orgânicos precisam seguir padrões rígidos ditados pela certificadora, principalmente de produção, que podem comprometer o resultado de toda a cadeia se forem descumpridos (Raynolds, 2004; Vieira et al., 2013; Rota et al., 2018). Além disto, há atributos de confiança que não podem ser verificados na análise física do produto e devem ser comunicados 
por meio de um sistema de controle representado por um selo ou certificação (Vieira, 2006; Hoppe et al., 2013).

Como contribuição teórica para a literatura de relações diádicas (comprador-fornecedor), no contexto de cadeias de suprimentos de alimentos orgânicos, comprovou-se que a utilização de incentivos competitivos auxiliam no cumprimento das legislações pertinentes à produção orgânica. Incentivos cooperativos foram utilizados essencialmente no estímulo à troca de informações relacionadas às práticas produtivas. Ainda, contribui-se com proposições teóricas para pesquisas futuras considerando-se as influências externas do contexto específico da produção orgânica na relação comprador-fornecedor. Como contribuição gerencial, o estudo revela como compradores podem utilizar diferentes tipos de incentivos competitivos e cooperativos para estimular o desempenho dos fornecedores. Dessa forma, considerando a visão do fornecedor e suas motivações em ser membro da cadeia, a empresa compradora pode potencializar ganhos relacionais, além dos resultados econômicos.

Além desta introdução, o artigo está organizado em quatro seções. A revisão de literatura é apresentada na segunda seção, enquanto o método de pesquisa é descrito na terceira. A caracterização das díades estudadas segue na seção quatro, junto à análise das evidências. As considerações finais encerram o presente artigo.

\section{Revisão da literatura}

O foco das pesquisas da área de cadeia de suprimentos tem se estendido de relações que têm como objetivo principal reduzir custos de transação (Williamson, 1985), para a qualidade das interações, mecanismos de governança utilizados nas trocas relacionais, aspectos colaborativos e de confiança (Rota et al., 2018). De acordo com essa perspectiva, a maioria dos recursos críticos requeridos para a geração de lucros acima da média (ganhos relacionais) está incorporada em relacionamentos, processos e rotinas interorganizacionais compartilhados (Obayi et al., 2017; Dyer et al., 2018).

Nas últimas décadas, diversas correntes de pesquisa com diferentes perspectivas em relacionamentos interorganizacionais têm analisado as relações entre comprador e fornecedor na cadeia de suprimentos: novas teorias institucionais como a Teoria dos Custos de Transação (TCT) (Williamson, 1985); a Teoria das Redes Sociais (Uzzi, 1997) e a Visão Relacional (Dyer \& Singh, 1998; Dyer et al., 2018). Adotaram-se, nesse estudo, os pressupostos da Visão Relacional, ancorada em quatro potenciais facilitadores de ganhos relacionais: (i) investimentos em ativos específicos na relação; (ii) intercâmbio substancial de conhecimento, a fim de gerar aprendizagem conjunta; (iii) a combinação de recursos ou capacidades complementares, com vistas a criar novos produtos, serviços, e/ ou tecnologias e (iv) a utilização de mecanismos de governança efetivos (Dyer \& Singh, 1998). Assim, compreender alguns padrões típicos de criação de valor em RIOs é útil, uma vez que pode ajudar a explicar como a alta confiança ou os laços repetidos não levam necessariamente a um melhor desempenho no relacionamento (Dyer et al., 2018).

\subsection{RIOs entre comprador e fornecedor em cadeias de suprimentos}

Uma unidade de análise cada vez mais importante para entender a vantagem competitiva é o relacionamento interorganizacional (RIO). Pesquisas empíricas têm demonstrado que relações integradas entre comprador $\mathrm{e}$ fornecedor podem enriquecer de maneira significativa o desempenho dos partícipes da díade (Krause et al., 1998; Chen \& Paulraj, 2004). Destacam, ainda, que a assimetria de poder pode influenciar os -RIOs- (Cox, 1999; Brito \& Miguel, 2017) e, por consequência, o desempenho da cadeia. No contexto de CS, é necessário construir relacionamentos e lidar com organizações que possuem experiências e valores diferentes. Isso implica promover um ambiente de confiança e colaboração entre as empresas da cadeia, que facilite a criação, o compartilhamento e a distribuição de conhecimento (Capó-Vicedo et al., 2011).

A literatura de RIOs é profícua em estudos sobre relações diádicas entre comprador e fornecedor, principalmente no desenvolvimento e avaliação de fornecedores (Huang et al., 2014; Tescari \& Brito, 2016). Mortensen \& Arlbjørn (2012) investigaram programas de desenvolvimento de fornecedores e salientaram a importância do interesse e a motivação dos fornecedores ao implementar iniciativas de desenvolvimento. Quando a empresa compradora concentra-se na visão do fornecedor e em suas motivações em ser membro da cadeia, obtém maior potencial nos benefícios adquiridos pela relação 
e potencializa os ganhos relacionais (Dyer \& Singh, 1998). Autry \& Golicic (2010) chegaram a resultados semelhantes por meio da análise de 323 relações diádicas. Os autores verificaram que o relacionamento influencia o desempenho e que os esforços dos compradores para construir e manter os RIOs fortes resulta em melhor desempenho de seus fornecedores.

De modo crescente, empresas compradoras percebem que o estabelecimento da conectividade e troca de informações com os parceiros a montante na CS é uma forma de desenvolvimento dos fornecedores, que é benéfico para ambos. Com base na literatura de CS e VR, Sanders et al. (2011) avaliaram o impacto do investimento do comprador em tecnologias de informações relacionadas com a conectividade sobre o desempenho da empresa fornecedora (survey com 218 empresas americanas e seus fornecedores diretos). Os resultados confirmaram que investimentos em tecnologia de informação realizados pelo comprador geram competitividade também ao fornecedor. Os achados geram recomendações práticas para os gestores em relação ao paradigma da VR, no qual investimentos em ativos específicos apresentam-se como fonte de vantagem competitiva para a díade.

Ainda, em relação aos RIOs, o estudo de Iwai \& Azevedo (2016) investigou como mecanismos de governança (incentivos econômicos ou baseados em processos interpessoais, especificamente na comunicação) podem influenciar uma suposta violação de confiança (evento negativo na relação). Por meio de um experimento composto por dois cenários para a cooperação, compararam, no nível cognitivo, os efeitos que as soluções estruturais (incentivos econômicos) e motivacionais (comunicação) exerciam sobre as crenças de confiança após um evento adverso. A experiência mostrou que, após um evento negativo, os relacionamentos em que a comunicação é usada para fomentar a cooperação estão associados a uma maior atribuição causal externa, maior benevolência/integridade percebida e maior disposição para conciliar e aceitar riscos relacionados ao comportamento dos outros. Esses achados sugerem que relacionamentos baseados em soluções motivacionais são mais resilientes a eventos negativos do que aqueles baseados em soluções estruturais.

Cabe mencionar o estudo de Tescari \& Brito (2016), que investigou a criação e a captação de valor através de um teste empírico (127 díades - empresas da indústria química brasileira) por meio de um modelo que separa o conceito de valor de relacionamento de acordo com duas fontes: as partes individuais (valor intrínseco) e a própria relação (valor relacional). $\mathrm{O}$ valor relacional considera (i) a colaboração e a interação, o qual é criado de maneira conjunta pelas partes; e (ii) o valor intrínseco, que deriva dos recursos e capacidades de cada partícipe do RIO, independente de atividades colaborativas. Os resultados identificaram que tanto os compradores quanto os fornecedores captam valor de seus relacionamentos. Contudo, o fornecedor pareceu obter uma percentagem mais elevada deste valor total. Nas díades estudadas, as partes identificaram benefícios específicos uns dos outros - valor intrínseco - e esse fato os motivava a se engajar em ações que levavam à criação de benefícios mútuos que então se traduziam em valor relacional.

A empresa compradora precisa considerar a motivação (fatores relacionais como troca de informação, comunicação, cooperação e confiança) (Gulati \& Sytch, 2007) e os interesses econômicos de seus fornecedores (Iwai \& Azevedo, 2016). Tal fato é importante já que a percepção de cada parte quanto aos benefícios que o RIO pode trazer adquire posição relevante no processo de tomada de decisão para a continuidade do negócio. Há, portanto, uma necessidade de geração continuada de benefícios mútuos, a fim de garantir que os fornecedores se sintam parte da relação, promovendo, assim, a continuidade do RIO (Tescari \& Brito, 2016).

\subsection{Incentivos competitivos e cooperativos nos RIOs entre comprador e fornecedor}

O comportamento das organizações enquanto participantes de RIOs pode ser o de cooperação ou competição. Cada comportamento tem um reflexo diferente sobre o desempenho das organizações da CS. Considerando-se o desempenho no relacionamento, o mesmo é conceituado como o grau em que atividades de trocas interorganizacionais são eficazes e eficientes (Boyle \& Dwyer, 1995), buscando garantir resultados econômicos (Iwai \& Azevedo, 2016). Assim, a empresa compradora pode desempenhar um papel importante no apoio à estratégia de operações dos partícipes, utilizando o desenvolvimento de fornecedores como uma ferramenta para auxiliar a ambos (Krause et al., 1998).

Terpend \& Krause (2015) subdividem os incentivos em competitivos e cooperativos. Incentivos competitivos 
referem-se a quando os fornecedores são recompensados nos negócios (presente e futuro) com base em seu desempenho em relação a outros fornecedores. Eles são baseados no mercado e concedidos de acordo com o desempenho do fornecedor e projetados para induzi-los a melhorar os resultados com base no desejo de aumentar o negócio com a empresa compradora (Krause et al., 2000). Materializam-se tipicamente sob a forma de ofertas de renovação de contrato, negócios adicionais ou aumento nos volumes de compra (Krause et al., 2000; Terpend \& Krause, 2015). A competição busca satisfazer os interesses próprios, sem considerar o impacto causado sobre as outras partes envolvidas na relação. $\mathrm{O}$ fornecedor é motivado por fatores extrínsecos a fim de garantir resultados econômicos (Iwai \& Azevedo, 2016). Isto é, certos comportamentos são adotados para receber incentivos ou evitar punições (Terpend \& Krause, 2015).

Já os incentivos cooperativos denotam uma partilha dos benefícios gerados em uma relação diádica entre comprador-fornecedor, com base em sua atuação conjunta, e não estão explicitamente condicionados ao desempenho de outros fornecedores. Exemplifica-se pela participação nos lucros, pela partilha de redução de custos, troca de informações, entre outros (Terpend \& Krause, 2015). Nos incentivos cooperativos, a motivação baseada em resultados econômicos é complementada por meio de benefícios sociais, como o desejo do fornecedor de se identificar com os compradores (relações de poder); a troca de conhecimentos com o comprador e a confiança estabelecida entre as partes (Terpend \& Krause, 2015). Assim, a parceria é mantida quando a confiança se torna parte integrante da relação.

Para que haja confiança é necessário desenvolver uma visão compartilhada e base comum de conhecimentos, reconhecer as diferenças, compromisso com a equidade $\mathrm{e}$ respeito às questões culturais (Geddes, 2014). A confiança tem natureza dinâmica e é dependente da história da relação (Iwai \& Azevedo, 2016).

Em complemento, o estudo de Terpend \& Krause (2015) valida alguns dos pressupostos da VR proposta por Dyer \& Singh (1998). Demonstra, por exemplo, que as empresas podem desenvolver vantagem competitiva em relação ao custo por meio de incentivos cooperativos. Um achado da pesquisa é a identificação do papel moderador do grau de dependência entre as partes na influência dos incentivos para o desempenho dos fornecedores. A cooperação parece ser eficaz apenas no caso de elevada dependência mútua.

A Figura 1 sintetiza a revisão de literatura sobre relacionamentos interorganizacionais diádicos na CS. Além do fluxo de informações e recursos na relação entre comprador-fornecedor, este pode se valer de incentivos cooperativos (na relação com cada fornecedor) e incentivos competitivos (na competição entre fornecedores) para estimular o desempenho dos fornecedores.

Figura 1. Incentivos na díade comprador-fornecedor. Fonte: Elaborada pelos autores.

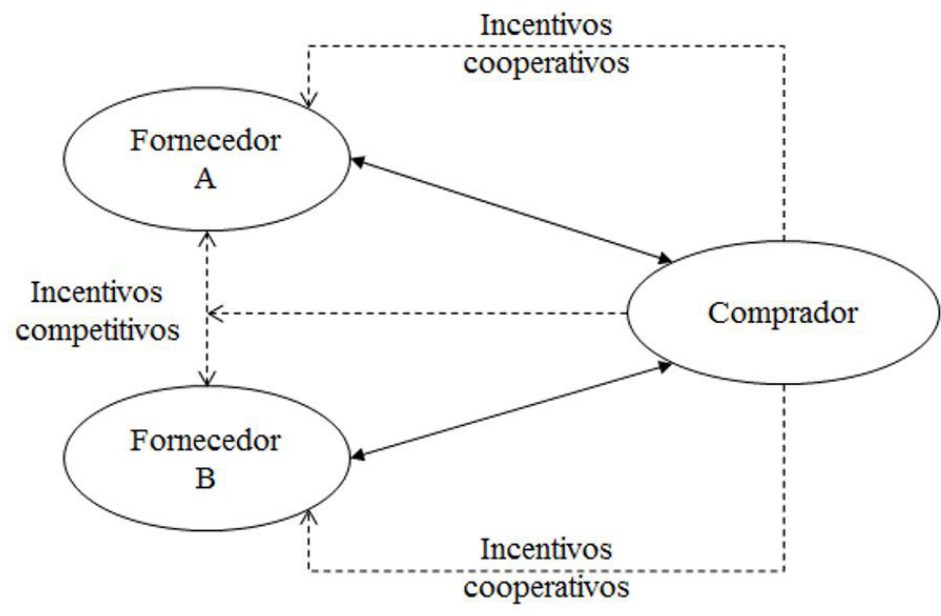

Legenda

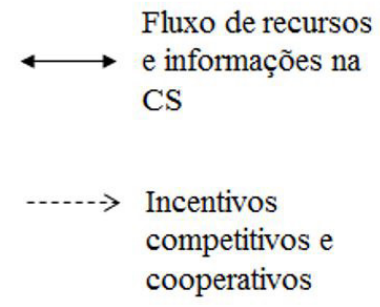

Resultados econômicos da díade 


\section{Método}

A pesquisa é de natureza qualitativa e descritiva, utilizando-se da estratégia de estudo de caso único (Yin, 2010). A unidade de análise está representada pelo relacionamento interorganizacional em díades compostas por uma indústria de alimentos orgânicos (agroindústria - empresa compradora) e seus produtores (fornecedores de matéria-prima - uva orgânica).

Por questões de confidencialidade, a empresa compradora será denominada Alpha Produtos Ecológicos e Naturais. Optou-se pela empresa Alpha devido à sua estratégia de utilização de produtos derivados da uva orgânica, com maior valor agregado e enfoque na qualidade e no processo produtivo e pelo contexto de inserção da empresa na CS de alimentos orgânicos, que representa um mercado em expansão em países em desenvolvimento como o Brasil (Vieira et al., 2013). Dados do Ministério da Agricultura, Pecuária e Abastecimento (Mapa) revelam que, nos últimos anos, o crescimento do interesse popular e o aumento no consumo impulsionaram a produção de orgânicos no Brasil (Ministério da Agricultura, Pecuária e Abastecimento, 2016).

A Alpha foi fundada em 1996, localiza-se na Serra Gaúcha e elabora produtos orgânicos, como sucos, vinagres, farinhas e óleos. Em 2016 empregava nove colaboradores, além de prestadores de serviços e trabalhadores temporários que são contratados no período da safra da uva, geralmente entre janeiro e fevereiro de cada ano. Conta com aproximadamente 30 produtores que cultivam a uva orgânica no sistema agroecológico de produção, quatro dos quais participaram da pesquisa. Foram selecionados produtores com tempo de relação maior do que cinco anos. Optou-se por preservar a identidade dos fornecedores e denominou-se de Produtor 1 (tem 0,6 hectares e fornece há 8 anos), Produtor 2 (possui 4,8 hectares e é fornecedor há 7 anos), Produtor 3 (tem 2,5 hectares e é fornecedor há 13 anos) e Produtor 4 (1,33 hectare e é um dos fornecedores mais antigos, há 19 anos).

\subsection{Coleta e análise de dados}

Para garantir a triangulação dos dados, ou seja, a utilização de diferentes tipos de evidências que visam aumentar a validade do estudo (Flick, 2004), e após definir a unidade de análise, a coleta de dados qualitativa ocorreu por meio de entrevistas semiestruturadas, análise documental e observações nas organizações pesquisadas. O Quadro 1 apresenta os detalhes sobre os procedimentos utilizados.

Os entrevistados foram os responsáveis pelos processos de compra e venda na díade, ou seja, na empresa Alpha a gerente de compras (que atua há 10 anos na organização) e o sócio-proprietário (fundador, que realiza a maioria das visitas aos fornecedores). No caso dos produtores, foram entrevistados os proprietários, que são responsáveis por todo o processo de produção (cultivo, colheita, acondicionamento e entrega), pela manutenção da certificação (atendendo aos critérios exigidos pela certificadora e normativas da empresa compradora) e também pela negociação e venda da uva orgânica.

O instrumento para a entrevista semiestruturada composto por perguntas abertas foi construído com base no estudo de Terpend \& Krause (2015) seguindo as categorias incentivos competitivos e cooperativos. Optou-se por questões distintas para a empresa compradora e para os fornecedores. Para a Alpha, na categoria incentivos competitivos, foram utilizadas

Quadro 1. Procedimentos de coleta de dados

\begin{tabular}{|l|l|}
\hline \multicolumn{1}{|c|}{ Fontes de evidências } & \multicolumn{1}{c|}{ Descrição } \\
\hline Entrevistas semiestruturadas & 2 entrevistas semiestruturadas na empresa Alpha e 4 entrevistas com produtores. \\
\hline Documentos internos da empresa Alpha & $\begin{array}{l}\text { Manual de procedimentos para o serviço do controle interno e boas práticas agrícolas } \\
\text { na produção de uvas orgânicas; Termo de compromisso de respeito às regras de } \\
\text { produção orgânica e o funcionamento do grupo; Plano de marketing e vendas; } \\
\text { Relatório do diagnóstico realizado pelo Projeto Extensão Industrial Exportadora - Peiex } \\
\text { desenvolvido pela Agência Brasileira de Promoção de Exportações e Investimentos } \\
(2015) ; \text { Instrução de Trabalho sobre o manejo orgânico - IT 017 revisão } 4 \text { de 10 de } \\
\text { dezembro de 2015 e Caderno de campo do Produtor 3. }\end{array}$ \\
\hline Observações não participantes & $\begin{array}{l}\text { 2 observações na empresa Alpha nos dias 11 de janeiro e 04 de novembro de 2016 e } \\
\text { 2 observações in loco nos Produtores 3 e 4 também no dia 04 de novembro de 2016. }\end{array}$ \\
\hline
\end{tabular}

Fonte: elaborado pelos autores. 
três perguntas abertas (ex: Existem recompensas pelo desempenho do fornecedor?) e para os cooperativos, quatro perguntas (ex: São desenvolvidas ações conjuntas com o fornecedor ' $x$ '?). No roteiro dos fornecedores foram utilizadas quatro perguntas abertas para os incentivos competitivos (ex: Há algum ranking de prioridade/preferência de fornecedores orgânicos?) e também quatro para os cooperativos (ex: Que tipo de suporte a Alpha oferece aos fornecedores?). O instrumento foi previamente validado por dois especialistas no tema de relacionamentos interorganizacionais e cadeias de suprimentos quanto a conteúdo e clareza das perguntas.

A coleta de dados ocorreu de novembro de 2015 a novembro de 2016. A empresa Alpha encaminhou os documentos internos em dezembro de 2015 e o roteiro de entrevista foi aplicado pessoalmente com a gerente administrativa em janeiro de 2016. A entrevista foi gravada (aproximadamente 30 minutos) e transcrita. Na oportunidade realizaram-se questões não estruturadas de cunho geral a fim de obter dados acerca da organização, com vistas a traçar um perfil (razão social, cargo do entrevistado, frequência da interação com os fornecedores, canais de relacionamento utilizados, interação da empresa compradora com outros elos da cadeia produtiva de orgânicos (certificadoras, agências reguladoras, consumidores), aspectos centrais do relacionamento no ponto de vista da Alpha e principais desafios (problemas, barreiras) enfrentados pela empresa no relacionamento com os fornecedores e como essas dificuldades são superadas).

Ainda, visitou-se a empresa e observaram-se processos e termos empregados entre os colaboradores. Devido ao período de safra da uva, não foi possível nessa ocasião visitar e aplicar o roteiro pessoalmente aos Produtores 1 e 2, que responderam diretamente à empresa compradora que repassou as respostas para aos pesquisadores. A coleta de dados foi complementada em novembro de 2016, por meio de entrevistas realizadas com o sócio-proprietário na sede da empresa Alpha e com os Produtores 3 e 4 nas respectivas propriedades. No mesmo período foram realizadas as observações não participantes que geraram memorandos detalhados a fim de complementar a análise.

Diante das categorias estabelecidas a priori para a coleta de dados, a análise baseou-se no conteúdo (Bardin, 2010). De acordo Bardin (2010), são três as principais fases para a organização desse modelo de análise: (i) a pré-análise: anterior à coleta de dados que embasou a construção do protocolo do estudo de caso e dos instrumentos de pesquisa qualitativa; (ii) a exploração do material: nessa etapa utilizaram-se diversas das técnicas específicas de análise de estudo de caso descritas por Yin (2010), como criação de matriz de categorias e disposição de evidências dentro dessas categorias (Quadro 2); classificação em tabelas por meio de documento de texto para as primeiras codificações e para o refinamento e utilização de fluxogramas e esquemas gráficos; e (iii) o tratamento dos resultados, a inferência e a interpretação: validações de especialistas dos dados e instrumentos e verificação pelos participantes (troca de e-mails com os entrevistados da empresa compradora).

O Quadro 2 detalha as categorias de análise utilizadas.

Em relação à confiabilidade utilizou-se um protocolo (roteiro de questões e observação não participante na sede da Alpha no momento das entrevistas e nos Produtores 2 e 3 nas respectivas propriedades) e uma base de dados desenvolvida com as categorias de análise, além dos documentos internos da díade (Yin, 2010).

\subsection{Contexto da produção de alimentos orgânicos}

De acordo com a International Federation of Organic Agriculture Movements (2016), a agricultura orgânica é um sistema de produção que visa assegurar a saúde dos solos, dos ecossistemas e das pessoas. São considerados produtos com maior valor na agricultura e no mercado de alimentos, especialmente em países em desenvolvimento, onde a disponibilidade ainda é baixa e restrita à renda dos consumidores (Vieira et al., 2013). Atualmente, a empresa comercializa suco de uva integral, vinagres de vinho e balsâmico, farinha de semente de uva e óleo de semente de uva. Utiliza-se de marca própria e comercializa seus produtos (orgânicos e certificados) em todo o País.

Os fornecedores da Alpha estão localizados em território nacional. Na CS da empresa compradora, diversas são as entidades reguladoras que fiscalizam as atividades desenvolvidas: Mapa, a Agência Nacional de Vigilância Sanitária (Anvisa) e a Ecocert, entidade privada que faz o controle e a auditoria dos processos de certificação orgânica, com ênfase na sustentabilidade ambiental e áreas correlatas (Ecocert, 2017). 
Quadro 2. Categorias de análise

\begin{tabular}{|c|c|c|c|}
\hline Categorias & Dimensões Empresa Focal & Dimensões Fornecedores & Autores de Base \\
\hline \multirow{8}{*}{ Incentivos competitivos } & \multirow{2}{*}{$\begin{array}{l}\text { Ranking de prioridade / } \\
\text { Avaliação do fornecedor }\end{array}$} & \multirow{2}{*}{ Ranking de prioridade } & Krause et al. (2000) \\
\hline & & & Terpend \& Krause (2015) \\
\hline & \multirow{2}{*}{ Procedimentos } & \multirow{2}{*}{ Procedimentos } & Terpend \& Krause (2015) \\
\hline & & & Brito \& Miguel (2017 \\
\hline & \multirow{2}{*}{-} & \multirow{2}{*}{$\begin{array}{l}\text { Qualidade da matéria prima } \\
\text { (uva orgânica) }\end{array}$} & Krause et al. (2000) \\
\hline & & & Terpend \& Krause (2015) \\
\hline & \multirow{2}{*}{ Recompensas ou punições } & \multirow{2}{*}{ Recompensas ou punições } & Terpend \& Krause (2015) \\
\hline & & & Iwai \& Azevedo (2016) \\
\hline \multirow{15}{*}{ Incentivos cooperativos } & \multirow{3}{*}{ Suporte oferecido } & \multirow{3}{*}{ Suporte recebido } & Sanders et al. (2011) \\
\hline & & & Terpend \& Krause (2015) \\
\hline & & & Brito \& Miguel (2017) \\
\hline & \multirow{2}{*}{ Troca de informações } & \multirow{2}{*}{ Troca de informações } & Capó-Vicedo et al. (2011) \\
\hline & & & Terpend \& Krause (2015) \\
\hline & \multirow{5}{*}{$\begin{array}{l}\text { Interação com outros elos } \\
\text { da cadeia produtiva de } \\
\text { orgânicos (certificadoras, } \\
\text { agências reguladoras) }\end{array}$} & \multirow{5}{*}{ Ações conjuntas } & Dyer \& Singh (1998) \\
\hline & & & Geddes (2014) \\
\hline & & & Terpend \& Krause (2015) \\
\hline & & & Tescari \& Brito (2016) \\
\hline & & & Brito \& Miguel (2017) \\
\hline & \multirow{5}{*}{$\begin{array}{l}\text { Compartilhamento das } \\
\text { estratégias }\end{array}$} & \multirow{5}{*}{$\begin{array}{l}\text { Conhecimento das estratégias } \\
\text { da empresa focal }\end{array}$} & Autry \& Golicic (2010) \\
\hline & & & Mortensen \& Arlbjørn (2012) \\
\hline & & & Datta \& Roy (2013) \\
\hline & & & Zimmermann \& Foerstl (2014) \\
\hline & & & Terpend \& Krause (2015) \\
\hline
\end{tabular}

Fonte: elaborado pelos autores com base em Terpend \& Krause (2015).

\section{Análise dos resultados}

\subsection{Incentivos competitivos}

Incentivos competitivos consistem em recompensas aos fornecedores de acordo com o seu desempenho em relação a outros (Krause et al., 2000; Terpend \& Krause, 2015). A primeira dimensão de análise considera as questões sobre ranking de prioridade e avaliação dos fornecedores. Os relatos dos entrevistados não indicaram a existência de um ranking de prioridade ou de preferência entre os fornecedores. Tampouco existem políticas de incentivos à competição entre os produtores, nem negócios adicionais ou aumento nos volumes de compra dependente do desempenho ou mesmo da quantidade e qualidade de uva produzida. "Todos são tratados da mesma forma" (gerente da Alpha). "Não há preferência entre os produtores" (Produtor 4).
Em relação aos procedimentos de seleção de fornecedores, de acordo com o sócio-proprietário, ocorre por meio das observações efetuadas pela equipe da Alpha "através de visitas a propriedades indicadas por outros produtores e por profissionais do setor". Para a qualificação desses fornecedores "existe um acompanhamento da empresa, de forma a demonstrar as exigências necessárias quando há a necessidade de conversão da produção convencional para a orgânica" (Sócio-proprietário). Produtores já certificados e que atendam à demanda da empresa são selecionados automaticamente. Tal situação converge com os critérios exigidos pela certificadora Ecocert que regula a produção orgânica.

O produtor no início da certificação assina um Termo de Compromisso de respeito às normas da produção orgânica. "Desde o início vai se criando uma relação de confiança entre as partes, e é esta relação que deve prevalecer para que se consiga levar a parceria adiante" (gerente da Alpha). No ponto de vista dos produtores, para ser 
fornecedor da Alpha deve-se respeitar as regras de produção orgânica e não aplicar nada que não seja permitido pelas leis. "Precisamos obedecer às regras que estão no Manual de Boas Práticas Agrícolas, informar sempre que algum vendedor vem oferecer algum produto para aplicação nas parreiras. Sinto dificuldade em produzir, porque existem poucos produtos permitidos no mercado a um preço acessível. É alto o custo de produção e o clima não tem colaborado para que tenhamos safras boas" (Produtor 1).

Analisando-se a Instrução de Trabalho 017, que visa estabelecer um procedimento padrão para o manejo orgânico realizado pelos produtores de uva e demais cuidados que devem ser seguidos de acordo com as exigências da Ecocert e da Alpha, verifica-se que a empresa compradora mantém registros e controle frequentes do processo produtivo, a fim de garantir que a matéria-prima (no caso, a uva) cumpra com as exigências da produção orgânica. De acordo com a gerente, os produtores são receptivos e abertos a fornecer as informações necessárias, e é rara a presença de não conformidades nos procedimentos. "O produtor que apresentar problemas, normalmente cumpre com as ações necessárias para corrigir a não conformidade" (gerente da Alpha). Na visita in loco aos Produtores 3 e 4 acompanhou-se a correção de uma não conformidade referente a uma solicitação da Ecocert, que prontamente foi atendida e resolvida pelos produtores com o auxílio do sócio-proprietário da Alpha.

Ainda de acordo com a IT 017, a quantidade de uva produzida é monitorada pela certificadora Ecocert. O preço médio pago por quilo independe da quantidade de uva entregue à Alpha, mas é medido pela qualidade. Segundo dados da gerente, entre 2013 e 2016 os produtores receberam quase três vezes mais por quilo, se comparado com o preço mínimo estipulado pelo mercado da uva Bordô, que é a variedade utilizada pela empresa compradora. "O valor recebido é acima da uva convencional, compensa, vale a pena, por isso que a gente se anima e cuida bem" (Produtor 3). As vinícolas da região serrana do Rio Grande do Sul, de maneira geral, costumam pagar o preço mínimo estipulado pelo mercado, enquanto a Alpha paga um valor quase três vezes superior por se tratar de uva orgânica. Essa política serve de estímulo à permanência do produtor e para o desenvolvimento de novos fornecedores (Sócio-proprietário).

No quesito qualidade da uva produzida, "o produtor deve seguir a IT 017 - Manejo Orgânico, anexada em cada caderno de campo" (gerente da Alpha). O Produtor 1 descreve que a qualidade é medida pelo grau $\mathrm{Babo}^{1} \mathrm{em}$ cada carga. Esse item também é evidenciado na fala do Produtor 2: "eles analisam a qualidade da uva colhida, não pode ter cachos podres, verdes, folhas, e o grau de açúcar, que é o principal".

Conforme questionamento sobre recompensas e ou punições oferecidos pela empresa compradora ao desempenho do fornecedor, a gerente descreve que não são oferecidas recompensas, tampouco punições. Porém, o pagamento acima do mercado, de acordo com o conceito de Krause et al. (2000) e Terpend \& Krause (2015), se configura como recompensa. Da mesma forma, as punições são relativas ao não cumprimento das normas internas determinadas pela Alpha e normas internacionais da produção orgânica. "As não conformidades são registradas $e$, conforme o caso, o fornecedor pode ser eliminado da listagem de fornecedores. Todo produtor é obrigado a seguir as Boas Práticas Agrícolas para a prevenção de possíveis perigos potenciais que não são eliminados no processo de elaboração de sucos e vinagres" (gerente da Alpha). Adicionalmente, o Produtor 1 destaca que: "se não respeitarmos as regras, somos descadastrados da empresa". A fala do Produtor 2 também reforça a categoria punição: "se não cumprir com as regras, não pode mais vender como orgânico". O Produtor 3 comenta que "não tem como enganar, se tu passa veneno eles vão descobrir".

Segundo dados coletados na entrevista com a gerente administrativa, a Alpha percebe o comprometimento e a seriedade quando o produtor preenche adequadamente o caderno de campo e quando as informações registradas acontecem na prática, "tudo observado durante as visitas realizadas" (gerente da Alpha). Os principais desafios do RIO citados foram: "o maior desafio é manter o produtor motivado a continuar produzindo de forma orgânica. Mesmo procurando remunerar o produtor com um percentual bem acima do valor da uva convencional, as alterações climáticas, perdas de safra e escassez de mão de obra são os principais gargalos nesta atividade. Este é o maior desafio e procura-se superá-lo através da valorização do produtor (remuneração justa) e constantes visitas de assessoria técnica para tentar minimizar os prejuízos" (Sócio-proprietário).

\footnotetext{
1 O grau glucométrico da uva é medido em escala de graus Babo, que representa a quantidade de açúcar, em peso, existente em $100 \mathrm{~g}$ de mosto (caldo da uva). Fonte: Guerra \& Zanus (2003).
} 


\subsection{Incentivos cooperativos}

A cooperação é refletida em esforços conjuntos e planejamento ao longo do tempo, utilizando-se de ações mútuas e considerada elemento fundamental para os RIOs (Chen \& Paulraj, 2004; Gulati \& Sytch, 2007). Considerando-se os exemplos de Terpend \& Krause (2015) como incentivos cooperativos (participação nos lucros, partilha de redução de custos, troca de informações, entre outros), evidenciaram-se na análise de dados que poucas são as ações proporcionadas pela Alpha que configuram esses incentivos.

O principal suporte oferecido ao fornecedor são os treinamentos e visitas. "Os produtores passam por um treinamento formal a cada dois anos, relativo às Boas Práticas Agrícolas, além dos treinamentos e assessorias informais, que acontecem a cada visita" (gerente da Alpha). Na fala do Produtor 1 as ações conjuntas se restringem a "assessoria técnica, e a empresa fornece as caixas de uva para a colheita". "Durante as visitas conversamos bastante, já teve um Encontro em que foi falado sobre a produção das uvas orgânicas e os direitos e deveres da empresa e de nós, produtores".

As visitas técnicas são realizadas tanto "pela certificadora (Ecocert)" quanto "pelo inspetor de Serviço de Controle Interno da Alpha". Nessas oportunidades "são feitas coletas de solo para análise, vistoria de toda a propriedade e verificação do Caderno de Campo-conforme IT 017, em que constam os procedimentos realizados" (gerente da Alpha). Complementa o sócio-proprietário que "o contato é pessoal e a comunicação direta por meio das visitas periódicas (mensais)". O documento para o acompanhamento é o caderno de campo que é entregue a cada produtor, com as orientações que devem ser rigorosamente seguidas. É considerado um histórico do parreiral e através dele os agentes envolvidos se atualizam sobre o que aconteceu na propriedade (IT 017). Na visita in loco realizada no Produtor 3 em novembro de 2016, pode-se observar o referido documento, no qual "anotamos quando começou a poda, quando começou a safra, se choveu, esfriou... todos olham o caderno de campo, o sócio-proprietário da Alpha, os inspetores do Ministério da Agricultura e os fiscais da certificadora" (Produtor 3).

Os treinamentos são vistos pela Alpha e por produtores como momentos de trocas de experiências e conhecimentos. O responsável pela preparação é o colaborador técnico de qualidade, junto ao técnico de Serviço de Controle Interno e a responsável pela qualidade. A cada produtor é entregue uma cartilha com os assuntos abordados no encontro, que podem ser: "responsabilidades nas Boas Práticas Agrícolas, Alimento Seguro e os perigos físicos, químicos e biológicos que podem ser encontrados na uva, critérios para o ingresso de novos produtores, procedimentos técnicos na produção, higienização dos equipamentos etc." (gerente da Alpha). Em média, cada treinamento dura duas horas e geralmente é realizado na sede da Alpha.

Ainda segundo a gerente, os produtores se mostram interessados, questionam e, acima de tudo, compreendem a importância de seguir as normas, para que "a Alpha consiga continuar crescendo e, consequentemente, podendo manter a parceria com os produtores". O Produtor 3 afirma que "a gente torce que a Alpha venda muito, que para nós é bom, quanto mais vendas, melhor, pois se a firma vai bem, nós vamos bem também".

Em relação à interação com outros elos da cadeia produtiva, destaca-se relato da gerente administrativa: "a procura pela uva orgânica tem sido bastante concorrida. No cenário atual não seria difícil encontrar outra indústria que adquirisse a produção dos atuais fornecedores. Mas os produtores permanecem com a Alpha por estes motivos: sempre se procura recompensá-los de forma justa para que tenham condições de continuar com este trabalho tão nobre, e pela relação que é construída sempre com muita dedicação e empatia. Eles fazem parte da família Alpha". De acordo com o Produtor 3, "concorrentes já nos procuraram, mas preferimos trabalhar com a Alpha. A Alpha começou pequenininha e tá crescendo e indo bem... a postura do sócio-proprietário é muito simples, temos confiança. E já conhecemos toda a família da empresa, outros produtores, por isso não trocamos".

Apesar dos trechos apresentados, não há participação nos resultados ou outro tipo de recompensa financeira oferecida pela Alpha aos fornecedores. Tampouco os fornecedores possuem conhecimento sobre as estratégias da empresa compradora. Conforme Diagnóstico Empresarial gerado no período de abril a setembro de 2015 (por meio de encontros mensais orientados por uma técnica extensionista) no Projeto de Extensão Industrial Exportadora (Peiex), a Alpha está se estruturando, e isso pode explicar a não utilização de outras formas de incentivos cooperativos com os fornecedores (Agência Brasileira de Promoção de Exportações e Investimentos, 2015). Ainda, identificou-se no diagnóstico que a área de Administração Estratégica da empresa compradora possui planejamento estratégico e organograma definidos; porém, não monitora o planejamento e não há sistema de informação integrado. 
Por outro lado, foi destacado por diversas vezes na fala dos entrevistados que a confiança na relação era um fator determinante da díade. De acordo com a gerente administrativa, para que se estabeleça a confiança e a cooperação entre as partes é necessário considerar a reputação e o tempo do relacionamento. "Neste caso é a reputação que o produtor tem perante a comunidade, a empresa e a sociedade em geral. Essa relação de confiança é construída com o tempo, através da relação do que deve ser feito e do que é realmente feito. A teoria e a prática devem andar juntas". Adiciona que "o relacionamento com os produtores é transparente e precisa ser de confiança mútua. É importante que o produtor cumpra com as normas orgânicas para que a parceria seja duradoura. É fundamental que ambos os lados desempenhem suas ações com responsabilidade e que os contatos sejam constantes".

\subsection{Discussão dos resultados}

Dyer \& Singh (1998) e Dyer et al. (2018) argumentam que vantagens competitivas podem ser obtidas em relacionamentos interorganizacionais por meio de investimentos em ativos específicos à relação; pelo estabelecimento de rotinas para a troca de conhecimento; pela complementaridade de recursos ou capacidades escassos e por mecanismos de governança efetivos, como os incentivos competitivos e cooperativos analisados neste estudo. $\mathrm{O}$ caso estudado apresentou evidências que confirmam esses elementos. Critérios como (i) contato pessoal entre os partícipes; (ii) intensa troca de informações (principalmente por meio de visitas, auditorias e treinamentos); (iii) comprometimento (com a qualidade - processos e produtos), seriedade (respeito às regras de produção), cooperação e confiança mútua; (iv) legitimidade da empresa compradora e (v) desafios do contexto da agricultura orgânica (intempéries, leis, entidades reguladoras, preços dos produtos) foram identificados ao longo da pesquisa.

Por meio da análise dos documentos, entrevistas e observações realizadas observou-se que a assimetria de poder é uma característica das díades estudadas. O poder é destacado no estudo com elementos relacionados à liderança no RIO, visto que a empresa compradora mantém um controle rígido sobre os produtores por meio de diversos mecanismos de controle, como caderno de campo, auditorias, assessoria técnica, preço pago pela matéria-prima maior do que a média do mercado, e até mesmo punições, como a aplicação de multa, ou o descredenciamento do produtor, conforme IT 017. A Alpha apresenta-se no estudo como a catalisadora das informações, mantendo contato com os principais órgãos reguladores da cadeia produtiva de orgânicos, como o Mapa, Certificadora e Vigilância Sanitária, a fim de compreender as normas e assegurar seu cumprimento. Assim, os fornecedores são motivados por fatores extrínsecos com o objetivo de garantir resultados econômicos (Iwai \& Azevedo, 2016).

Mesmo assim, pode-se considerar que existe sinergia nas relações e que o contato pessoal é percebido como um incentivo cooperativo no RIO, gerando cooperação, confiança, legitimidade e reputação (Iwai \& Azevedo, 2016; Terpend \& Krause, 2015). Por outro lado, as díades da pesquisa reforçam os pressupostos de Mortensen \& Arlbjørn (2012), pois, na visão do fornecedor, a empresa compradora obtém maior retorno nos incentivos, potencializando os ganhos relacionais. Logo, é evidente a necessidade de manter benefícios mútuos, garantindo que os fornecedores se sintam parte da relação, promovendo, assim, a continuidade do RIO e a geração de ganhos não somente econômicos, mas também relacionais (Brito \& Miguel, 2017; Tescari \& Brito, 2016).

Considerando-se a complexidade da agricultura orgânica (intempéries, leis, entidades reguladoras, preços dos produtos) (International Federation of Organic Agriculture Movements, 2016), as evidências comprovaram a importância das entidades reguladoras e identificou-se uma categoria composta por fatores externos ou institucionais. Esses fatores influenciam diretamente os relacionamentos interorganizacionais e são fundamentais para a continuidade das relações diádicas da cadeia. São muitas as normas e princípios estabelecidos para a produção de orgânicos, principalmente com ênfase no impacto do processo no ambiente (Vieira et al., 2013); por isso, diversos são os procedimentos a serem realizados durante a produção, colheita e entrega da uva orgânica e as punições são evitadas por meio dos comportamentos adotados pelos produtores que prezam, acima de tudo, manter o fornecimento. Isso reflete nos resultados econômicos de ambas as organizações, conforme preconizado por Iwai \& Azevedo (2016) e Terpend \& Krause (2015) e exige da empresa compradora treinamentos, acompanhamento e controles rígidos nos procedimentos adotados por seus fornecedores. Sendo 
assim, apresenta-se como contribuição deste estudo a seguinte proposição:

Proposição 1: Fatores externos/institucionais influenciam a utilização de incentivos competitivos a fim de garantir a continuidade das relações diádicas entre compradores-fornecedores no contexto da produção de alimentos orgânicos.

Apesar das características do contexto analisado, a empresa compradora reconhece a motivação e interesse de seus fornecedores em continuar a produzir a uva orgânica e permanecer no RIO. No estudo de Terpend \& Krause (2015), a cooperação se mostrou eficaz em casos de elevada dependência, convergente ao caso estudado. A assimetria de poder na relação e a dependência do fornecedor com a empresa compradora (remuneração acima da média) e os fatores externos/institucionais da produção orgânica, como as certificações exigidas, são fato corrente. Porém, principalmente a assimetria poderia ser diminuída com uma participação mais intensa dos fornecedores no dia a dia da Alpha, proporcionando a aprendizagem mútua e constante, não somente uma transferência de conhecimentos. É vital para a continuidade da relação a busca do alinhamento do comportamento do fornecedor com os objetivos da empresa compradora (Terpend \& Krause, 2015). Dessa maneira, a segunda proposição teórica é descrita:

Proposição 2: A adoção de incentivos cooperativos pela empresa compradora tem efeito positivo sobre a influência dos fatores externos / institucionais na relação diádica.

Diante do exposto, no estudo de caso pesquisado, observou-se a falta de uma gama de ações conjuntas e, por consequência, o não compartilhamento de objetivos estratégicos entre as empresas, fatores que prejudicam o desenvolvimento da parceria. No diagnóstico foi identificado que a área de Administração Estratégica da Alpha possui planejamento estratégico e organograma definidos, porém, não monitora o planejamento e não há sistema de informação integrado. Tal situação diverge do estudo de Sanders et al. (2011), que aponta que investimentos em recursos de informação realizados pelo comprador geram competitividade também ao fornecedor, apresentando que investimentos em ativos específicos podem ser uma fonte de vantagem competitiva para ambas as partes, reforçando o pressuposto da VR (Dyer \& Singh, 1998).

Considerando-se o objetivo da pesquisa de analisar como os incentivos competitivos e cooperativos originários da empresa compradora podem influenciar nos resultados econômicos dos fornecedores, apresenta-se o Quadro 3, que sintetiza os resultados.

Ainda, a fim de contribuir para a expansão dos estudos entre comprador-fornecedor, pode-se observar, pela análise das categorias incentivos competitivos e cooperativos, o surgimento de novos insights. Emerge dos dados uma categoria distinta que considera os fatores externos/institucionais como determinantes ao sucesso da relação diádica.

Quadro 3. Síntese dos resultados

\begin{tabular}{|c|c|c|}
\hline Categorias & Conceitos & Fatores relacionados \\
\hline Incentivos competitivos & \multirow{2}{*}{$\begin{array}{l}\text { Baseados no mercado e os fornecedores são } \\
\text { recompensados nos negócios (presente e futuro) } \\
\text { com base em seu desempenho em relação aos } \\
\text { demais fornecedores. }\end{array}$} & \multirow[b]{2}{*}{$\begin{array}{l}\text { Pagamento acima da média do mercado por } \\
\text { quilo da fruta. }\end{array}$} \\
\hline (Terpend \& Krause, 2015) & & \\
\hline Incentivos cooperativos & \multirow[b]{2}{*}{$\begin{array}{l}\text { Baseados na atuação conjunta (comprador- } \\
\text { fornecedor). A motivação por resultados } \\
\text { econômicos é complementada pelos benefícios } \\
\text { sociais e a cooperação e a confiança são dimensões } \\
\text { estabelecidas na díade. }\end{array}$} & \multirow[b]{2}{*}{$\begin{array}{l}\text { Troca de informações por meio de assessoria técnica } \\
\text { constante e de maneira pessoal, principalmente } \\
\text { em treinamentos e visitas técnicas. Presença de } \\
\text { dimensões constituintes de RIOs, como confiança, } \\
\text { legitimidade e reputação, que geram ganhos } \\
\text { relacionais aos partícipes. }\end{array}$} \\
\hline (Terpend \& Krause, 2015) & & \\
\hline Fatores externos / institucionais & \multirow[b]{2}{*}{$\begin{array}{l}\text { Dependentes da atuação dos órgãos fiscalizadores } \\
\text { da produção de alimentos orgânicos. A motivação } \\
\text { por resultados econômicos estimula a empresa } \\
\text { compradora a fiscalizar os procedimentos, a fim } \\
\text { de que as exigências sejam cumpridas pelos } \\
\text { fornecedores. }\end{array}$} & \multirow[b]{2}{*}{$\begin{array}{l}\text { A empresa compradora monitora e comunica } \\
\text { aos fornecedores as legislações pertinentes a } \\
\text { produção orgânica e garante que as Boas Práticas } \\
\text { Agrícolas sejam executadas. Acompanha e auxilia } \\
\text { nas certificações e fiscaliza os procedimentos de } \\
\text { seus fornecedores. }\end{array}$} \\
\hline (nova categoria) & & \\
\hline
\end{tabular}

Fonte: elaborado pelos autores. 


\section{Implicações e considerações finais}

Em resposta à questão problema da investigação de como os incentivos da empresa compradora afetam os resultados econômicos do fornecedor, evidenciou-se que, além dos incentivos competitivos e cooperativos preconizados por Terpend \& Krause (2015), na cadeia de alimentos orgânicos pesquisada, uma nova categoria emergiu da análise dos dados, descrita no estudo como fatores externos / institucionais. Devido à assimetria de poder na relação, os produtores são afetados diretamente pelas ações da organização compradora. A governança da cadeia é influenciada pelos órgãos responsáveis pelas certificações internacionais que exigem o cumprimento de diversos requisitos. Os produtores tornam-se dependentes da empresa compradora que catalisa as informações, e a empresa compradora confia que seu fornecedor seja correto na prestação de serviços. Esse resultado confirma os argumentos de Terpend \& Krause (2015) de que a cooperação do RIO aumenta quando existe alta dependência entre os partícipes.

O principal incentivo competitivo do RIO é a remuneração acima da média do mercado. Da mesma maneira, são restritos os incentivos cooperativos analisados nos relacionamentos diádicos estudados. Estes foram, principalmente, a prestação de serviços de maneira pessoal por meio de assessoria técnica (visitas e treinamentos) e a confiança gerada ao longo da relação. O retorno financeiro, a confiança e a interação constante para o aperfeiçoamento das técnicas produtivas utilizadas, visitas e treinamentos para o cumprimento dos requisitos da agricultura orgânica, motivam os produtores a permanecer no segmento e priorizar a qualidade do produto comercializado.

O principal ativo gerado na relação é o conhecimento que o fornecedor recebe da empresa compradora, mas é escassa a geração de novas aprendizagens, especialmente informações de cunho mercadológico e gerenciais que poderiam auxiliar o produtor a agregar mais valor ao seu produto e valorizar a relação (Brito \& Miguel, 2017). A empresa compradora é a transmissora de informações técnicas necessárias ao cumprimento dos requisitos da agricultura orgânica, e o produtor, um receptor. $\mathrm{O}$ caso estudado não reflete as experiências apresentadas por Brito \& Miguel (2017), Terpend \& Krause (2015) e Tescari \& Brito (2016), pois a empresa compradora não possui indicadores de desempenho nem planos de incentivos formais, tampouco identifica que a utilização desses benefícios pode proporcionar melhorias no desempenho de seus fornecedores e do RIO de maneira geral, pois ambas as empresas poderiam captar maior valor em suas relações.

Apesar das dificuldades do setor apresentadas pelos entrevistados, os partícipes apontam para o incentivo cooperativo da confiança recíproca. Os fornecedores estudados já se relacionam com a empresa compradora há um período considerável de tempo, confirmando que as relações entre compradores e fornecedores são cíclicas e tendem a evoluir em espiral ao longo do tempo (Autry \& Golicic, 2010). Ainda, de acordo com a análise dos dados, as relações diádicas se tornaram mais fortes como resultado das ações desenvolvidas na trajetória do RIO. A necessidade de se considerar os fatores relacionais e do fornecimento de benefícios mútuos, promovendo a motivação dos fornecedores pela empresa compradora converge com os estudos de Iwai \& Azevedo (2016) e Tescari \& Brito (2016).

Como contribuição teórica para o campo dos RIOs, em especial aos relacionamentos diádicos compradorfornecedor na cadeia de suprimentos de alimentos orgânicos, o estudo descreve o papel de incentivos competitivos e cooperativos, e introduz uma nova categoria de fatores externos/institucionais, que indica a influência das regulamentações internacionais e nacionais e os custos de certificação na governança das relações. Na agricultura orgânica, os órgãos certificadores representam um papel de destaque na governança da cadeia e alteram os relacionamentos interorganizacionais dos partícipes que necessitam cumprir as rigorosas exigências da produção. Evidenciaram-se pela pesquisa os benefícios para as empresas compradoras em utilizar como prática o uso de incentivos. Com isso, elas tornam-se aptas a gerenciar pró-ativamente o desempenho de seus fornecedores e, sobretudo, estimular o desenvolvimento dos RIOs, reafirmando estudos anteriores realizados em outros contextos (Autry \& Golicic, 2010; Iwai \& Azevedo, 2016; Mortensen \& Arlbjørn, 2012; Sanders et al., 2011).

Como contribuição gerencial, o estudo demonstra que a relação das empresas compradoras com seus fornecedores pode ser fortalecida por meio da utilização de incentivos que visem o estabelecimento de uma relação do tipo ganha-ganha. As ações gerenciadas pelos compradores refletem diretamente no desempenho dos fornecedores e precisam ser direcionadas à melhoria da trajetória 
da relação considerando-se os pressupostos da Visão Relacional, como investimentos em ativos específicos, intercâmbio de conhecimentos, combinação de recursos ou capacidades e redução dos custos de transação.

O estudo se limita a identificar os incentivos competitivos e cooperativos de relacionamentos entre comprador-fornecedor. Contudo, diante da análise dos dados, duas proposições teóricas foram apresentadas de acordo com os resultados obtidos no estudo por meio das evidências empíricas. Destaca-se, aqui, a importância das regras internacionais da produção orgânica (Mapa, 2016) e atributos de confiança que influenciam nas relações entre comprador e fornecedor (Hoppe et al., 2013). Essas proposições podem ser trabalhadas em outros estudos como sugestão de pesquisas futuras, a fim de ampliar o conhecimento da influência de fatores externos/institucionais na cadeia de alimentos orgânicos.

Estudos futuros podem avançar na compreensão da governança de relacionamentos diádicos, analisando os mecanismos formais e informais aplicados de forma integrada em RIOs, explorando as mudanças de mecanismos ao longo do tempo, e se o uso desses mecanismos influencia a geração de ganhos relacionais. Dessa forma, a base teórica também poderia ser ampliada, utilizando-se além da Visão Relacional, a Teoria dos Custos de Transação, de forma a complementar as questões relativas aos atributos tangíveis nas trocas relacionais (Oliveira \& Santana, 2012; Cunha et al., 2015).

Sugere-se também a ampliação da pesquisa com os demais fornecedores, e o estudo de outras organizações do mesmo setor que trabalhem com produtos orgânicos, permitindo comparar os tipos de incentivos utilizados e seus resultados. É possível, ainda, ampliar o estudo para outros segmentos e com a participação de outros elos da cadeia de suprimentos, além de díades as tríades ou a cadeia como um todo.

\section{Referências}

Agência Brasileira de Promoção de Exportações e Investimentos - APEXBRASIL, \& Projeto Extensão Industrial Exportadora - PEIEX. (2015). Relatório do diagnóstico da Alpha. Garibaldi: Apex Brasil.

Autry, C. W., \& Golicic, S. L. (2010). Evaluating buyersupplier relationship performance spirals: A longitudinal study. Journal of Operations Management, 28, 87-100.
Bardin, L. (2010). Análise de conteúdo (3. ed.). Lisboa: Edições 7.

Boyle, B. A., \& Dwyer, F. R. (1995). Power, bureaucracy, influence, and performance: their relationships in industrial distribution channels. Journal of Business Research, 32, 189-200.

Braziotis, C., Bourlakis, M., Rogers, H., \& Tannock, J. (2013). Supply chains and supply networks: distinctions and overlaps. Supply Chain Management, 18(6), 644-652.

Brito, R. P., \& Miguel, P. L. S. (2017). Power, governance, and value in collaboration: differences between buyer and supplier perspectives. The Journal of Supply Chain Management, 53(2), 61-87.

Capó-Vicedo, J., Mula, J., \& Capó, J. (2011). A social network-based organizational model for improving knowledge management in supply chains. Supply Chain Management, 16(5), 379-388.

Chen, I. J., \& Paulraj, A. (2004). Towards a theory of supply chain management: the constructs and measurement. Journal of Operations Management, 22(2), 119-150.

Cheung, M. S., Myers, M. B., \& Mentzer, J. T. (2010). Does relationship learning lead to relationship value? A cross-national supply chain investigation. Journal of Operations Management, 28, 472-487.

Cox, A. (1999). Power, value and supply chain management. Supply Chain Management, 4(4), 167-175.

Cunha, C. F. D., Saes, M. S. M., \& Mainville, D. Y. (2015). Custos de transação e mensuração na escolha da estrutura de governança entre supermercados e produtores agrícolas convencionais e orgânicos no Brasil e nos EUA. Gestão E Produção, 22(1), 67-81.

Datta, P. P., \& Roy, R. (2013). Incentive issues in performancebased outsourcing contracts in the UK defence industry: a simulation study. Production Planning and Control, 24(4-5), 359-374.

Daugherty, P. J. (2011). Review of logistics and supply chain relationship literature and suggested research agenda. International Journal of Physical Distribution $\mathcal{E}$ Logistics Management, 41(1), 16-31.

Dyer, J. H., \& Singh, H. (1998). The relational view: cooperative strategy and sources of inter-organizational competitive advantage. Academy of Management Review, 24(4), 660-679.

Dyer, J. H., Singh, H., \& Herterly, W. S. (2018). The relational view revisited: a dynamic perspective on value creation and value capture. Strategic Management Journal, 39(12), 3140-3162.

Ecocert. (2017). Atividades. Recuperado em 10 de janeiro de 2017, de http:/ / brazil.ecocert.com/nossas-atividades

Flick, U. (2004). Triangulation in qualitative research. In U. Flick, E. Von Kardoff \& I. Steinke (Eds.), A companion to qualitative research. New York: SAGE. 
Geddes, M. (2014). Relacionamentos interorganizacionais no desenvolvimento de parcerias locais e regionais. In S. Crooper, M. Ebers, C. Huxham \& P. S. Ring (Eds.), Handbook de relações interorganizacionais da Oxford (cap. 8, p. 183-208). Porto Alegre: Bookman.

Gulati, R., \& Sytch, M. (2007). Dependence asymmetry and joint dependence in interorganizational relationships: effects of embeddedness on a manufacturer's performance in procurement relationships. Administrative Science Quarterly, 52, 32-69.

Guerra, C. C., \& Zanus, M. C. (2003). Uvas viníferas para processamento em regiões de clima temperado (Sistema de Produção, 4). Embrapa Uva e Vinho. Recuperado em 31 de janeiro de 2016, de https:// sistemasdeproducao.cnptia.embrapa.br/FontesHTML/ Uva/UvasViniferasRegioesClimaTemperado/colheita.htm

Hoppe, A., Vieira, L. M., \& Barcellos, M. D. D. (2013). Consumer behaviour towards organic food in Porto Alegre: an application of the theory of planned behaviour. Revista de Economia e Sociologia Rural, 51(1), 69-90.

Huang, M. C., Yen, G. F., \& Liu, T. C. (2014). Reexamining supply chain integration and the supplier's performance relationships under uncertainty. Supply Chain Management, 19(1), 64-78.

International Federation of Organic Agriculture Movements -IFOAM. (2016). Definition of organic agriculture. Recuperado em 02 de abril de 2016, de http: / / www.ifoam.bio/ en / organic-landmarks / definition-organic-agriculture

Iwai, T., \& Azevedo, P. F. (2016). Economic incentives or communication: how different are their effects on trust. $B A R, 3(3), 1-25$.

Krause, D. R., Handfield, R. B., \& Scannell, T. V. (1998). An empirical investigation of supplier development: reactive and strategic processes. Journal of Operations Management, 17, 39-58.

Krause, D. R., Scannell, T. V., \& Calantone, R. J. (2000). A structural analysis of the effectiveness of buying firms' strategies to improve supplier performance. Decision Sciences, 31(1), 33-55.

Ministério da Agricultura Pecuária e Abastecimento - MAPA. (2016). Orgânicos. Recuperado em 10 de janeiro de 2016, de http:/ / www.agricultura.gov.br/ desenvolvimento-sustentavel/organicos

Mortensen, M., \& Arlbjørn, J. (2012). Inter-organisational supplier development: the case of customer attractiveness and strategic fit. Supply Chain Management, 17(2), 152-171.

Obayi, R., Koh, S. C., Oglethorpe, D., \& Ebrahimi, S. M. (2017). Improving retail supply flexibility using buyersupplier relational capabilities. International Journal of Operations E Production Management, 37(3), 343-362.
Oliveira, C. M. D., \& Santana, A. C. D. (2012). A governança no arranjo produtivo de grãos de Santarém e Belterra, estado do Pará: uma análise a partir do grão soja. Revista de Economia e Sociologia Rural, 50(4), 683-704.

Oliver, C. (1990). Determinants of interorganizational relationships: integration and future directions. Academy of Management Review, 15(2), 241-265.

Raynolds, L. T. (2004). The globalization of organic agro-food networks. World Development, 32(5), 725-743.

Rota, C., Pugliese, P., Hashem, S., \& Zanasi, C. (2018). Assessing the level of collaboration in the Egyptian organic and fair trade cotton chain. Journal of Cleaner Production, 170, 1665-1676.

Sanders, N. R., Autry, C. W., \& Gligor, D. M. (2011). The impact of buyer firm information connectivity enablers on supplier firm performance. International Journal of Logistics Management, 22(2), 179-201.

Terpend, R., \& Krause, D. R. (2015). Competition or cooperation? Promoting supplier performance with incentives under varying conditions of dependence. The Journal of Supply Chain Management, 51(4), 29-53.

Tescari, F. C., \& Brito, L. A. L. (2016). Value creation and capture in buyer-supplier relationships: a new perspective. $R A E, 56(5), 474-488$.

Uzzi, B. (1997). Social structure and competition in interfirm networks: the paradox of embeddedness. Administrative Science Quarterly, 42(1), 35-67.

Viana, F. L. E., Neto, J. P. B., \& Añez, M. E. M. (2014). Gestão da cadeia de suprimento e vantagem competitiva relacional nas indústrias têxtil e de calçados. Gestão $\mathcal{E}$ Produção, 21(4), 836-852.

Vieira, L. M. (2006). O impacto das normas alimentares públicas e privadas na coordenação da cadeia da carne bovina: um estudo exploratório. Revista ADM, 41(1), 69-80.

Vieira, L. M., Barcellos, M. D., Hoppe, A., \& Silva, S. B. (2013). An analysis of value in an organic food supply chain. British Food Journal, 115(10), 1454-1472.

Villena, V. H., Revilla, E., \& Choib, T. Y. (2011). The dark side of buyer-supplier relationships: A social capital perspective. Journal of Operations Management, 29, 561-576.

Williamson, O. E. (1985). The economic institutions of capitalism. New York: Free Press.

Yin, R. K. (2010). Estudo de caso: planejamento e métodos (4. ed.). Porto Alegre: Bookman.

Zimmermann, F., \& Foerstl, K. (2014). A meta-analysis of the "purchasing and supply management practiceperformance link". The Journal of Supply Chain Management, 50(3), 37-54. 